\title{
Management of Acquired Anterior Mandibular defect with an Endosseous Implant-supported Fixed Partial Denture: A Clinical Report
}

B.Thirupathi Reddy ${ }^{1}$, M.Dhanraj ${ }^{2}$, EGR.Solomon $^{3}$, G.Sivagami $^{4}$

${ }^{1} \mathrm{PG}$, student, ${ }^{2}$ Reader, ${ }^{3}$ Emeritus professor, ${ }^{4}$ Prof and Head, Department of Prosthodontics \& Implantology

B.Thirupathi Reddy, M.Dhanraj, EGR.Solomon, G.Sivagami

Management of Acquired Anterior Mandibular defect with an Endosseous Implant-supported Fixed Partial

Denture: A Clinical Report. Tanz Dent J 2009; 15(2):42-44

\begin{abstract}
The application of endosseous implant therapy in conjugation with bone augmentation has tremendously improved the quality of reconstruction of maxilla and mandible over the last decade and has allowed for improved results. This clinical report describes the management of anterior mandibular continuity defect due to road traffic accident with anterior superior segmental reconstruction and placement of four Osseointegrated implants with fixed partial denture.
\end{abstract}

Correspondence: Dr.B.Thirupathi Reddy, Saveetha Dental College, Chennai, E-mail: smiledrreddy@gmail.com

\begin{abstract}
Introduction
During the past few decades the practice of dentistry has changed with the introduction of endosseous implants. Patients with acquired mandibular defects due to trauma often need a multidisciplinary approach to regain appropriate function, esthetics and comfort $(1,2)$. The invasive nature of the defects makes the prosthetic reconstruction of maxilla and mandible difficult without a pre-surgical phase (3).
\end{abstract}

The reconstruction to restore the structural integrity and continuity of the defects which includes the alveolar ridge often require surgical augmentation with bone grafting to provide a reasonably good residual ridge $(4,5)$. In the past, removable partial denture was the choice as a prosthetic replacement. The retention of these prostheses often becomes difficult due to soft and hard tissue undercuts and compromised periodontal status. Further, unesthetic appearance with visible components of the retainers and other components of partial denture should also be considered. The placement of endosseous implants together with autogenous bone grafting could overcome these limitations. A case of mandibular road traffic accident with extensive anterior mandibular defect restored with anterior superior segmental reconstruction with an "implant retained fixed partial denture" is reported

\section{Clinical report}

A male patient, aged 24 years, reported to the Department of Prosthodontics and Implantology with a chief complaint of missing lower anterior and left first premolar and second premolar [constituting Kennedy's class IV], compromised esthetics and difficulty in pronunciation. History revealed the patient had met with a road traffic accident and earlier underwent surgery to correct the mid-mandibular fracture in parasymphysis region with two compression miniplates. The lower anterior teeth $42,41,31,32,33,34$, and 35 were fractured and then were extracted. After sufficient bone healing the miniplates were removed. On intra oral examination 42,41,31,32,33,34, and 35 were missing and the corresponding edentulous ridge appeared depressed, the tissues exhibited complete healing. The soft tissue overlying the edentulous alveolar ridge showed good signs of healing. Other teeth present exhibited an optimum periodontal health. Radiological examination revealed marked alveolar bone loss from right central incisor to left second premolar region and the patient was diagnosed as type $\mathbf{V}$ Cantor and Curtis mandibular defect (6), (fig-1). Patient was surgically treated in the Department of Oral and Maxillofacial surgery to correct bone loss and enhance ridge augmentation by autogenous iliac bone graft. After the healing phase, implant placement in the edentulous site was planned in lieu of cast partial denture since the patient did not prefer a removable prosthesis. Ceramic bridge was not indicated because it was not the patient's preference as he did not like preparation of the natural teeth for abutment. Considering the clinical situation a "implant- supported fixed partial denture was recommended.

\section{Procedure}

Diagnostic casts were articulated with face-bow transfer and surgical template prepared with clearauto polymerizing resin. Surgical template was inserted in the patient mouth and bone mapping done to select the site for implant placement as well 
as to obtain the diameter of implants. With bone mapping and radiographic evaluation it was possible to assess the topography and quality of available bone. Based on these evaluation four endosseous implants were selected [Zimmer-Screw vent/USA type, $\quad 4.7 \mathrm{~mm} / 16 \mathrm{~mm}, \quad 3.7 \mathrm{~mm} / 13 \mathrm{~mm}$ anteriorly and $3.7 \mathrm{~mm} / 8 \mathrm{~mm}, \quad 3.7 \mathrm{~mm} / 8 \mathrm{~mm}$ posteriorly].

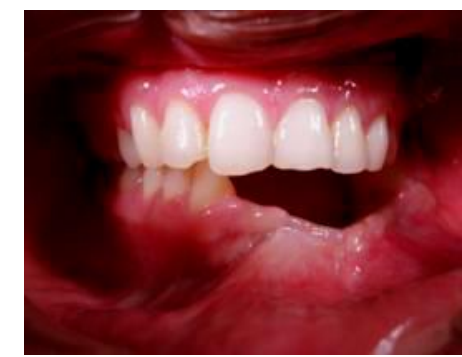

Fig-1: Type v CANTOR \& CURTIS

Mandibular defect pre-operative

After local anaesthesia a full thickness mucoperiosteal flap was elevated, osteotomy drills were sequenced and sites were prepared. Paralleling pins were placed and relative parallelism (fig-2) of implants was perfected and four implants were placed. The flap was approximated and sutured.

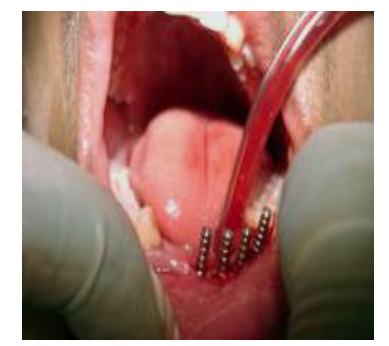

Fig -2: Paralleling pins in place to check the parallelism of the implants

Immediate orthopantomogram was taken to ascertain the positioning and parallelism of implants (fig-3). Post-surgical instructions were given and patient was recalled after 1 week for suture removal and post operative healing was satisfactory.

A transitional partial denture was fabricated to maintain phonetics and to assess the overjet and over bite. Osseointegration of implants was assessed periodically and implants showed good osseointegration and healing.

Patient was recalled after 3 months for the stage two surgery. The implant site was exposed and healing abutments were placed. Implant fixtures with transfer copings were then fixed on embedded implants and double mix addition silicone [Aquasil/Dentsply, Germany] impression was made by an indirect transfer technique. Suitable implant analogs were then placed and cast was prepared. Abutments were placed over the analogs. They were modified in the cast and then tried in patient's mouth for precision and adequate clearance during centric and lateral excursions.

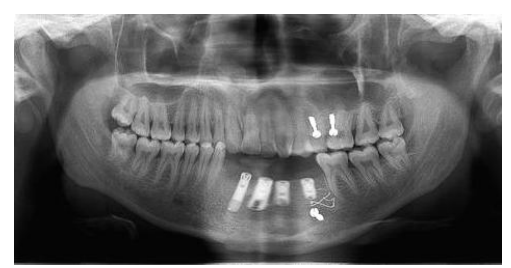

Fig -3: Ortho Phantamo gram immediately after implant placement

Facebow [Hanau earpiece spring Type, Waterpik, USA] transfer was secured and casts were articulated in semi adjustable articulator [Hanau wide vue 2 , USA]. The wax patterns were fabricated and casted and a metal try-in was done for adequate clearance. Gingival shade was matched for gingival veneering to mimic the adjacent teeth.

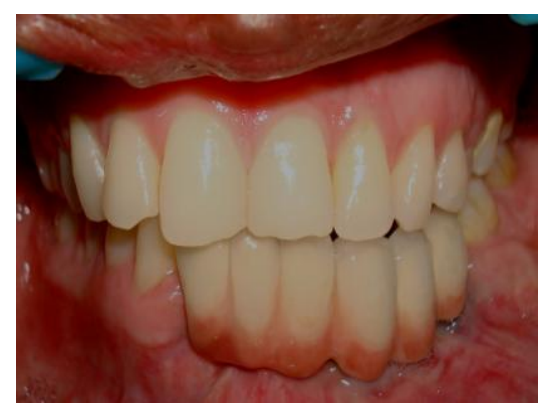

Fig-4: Facial view of the final prosthesis

Ceramic try-in was done after the bisque bake stage and occlusal discrepancies were corrected and subsequently fired and glazed. Implant prosthesis was tried in the mouth for patients satisfaction, comfort, esthetics, marginal adaptability and occlusion (fig-4). After a provisional cementation for a week, the prosthesis was luted with Type I Glass ionomer cement (7) [GC Fuji - I, Japan].

\section{Discussion}

The art of implant dentistry with increasing esthetic expectations of the patients often challenges the conventional methods of replacing teeth, especially in mandibular resection defects. In such cases surgical intervention with bone grafting often becomes imminent prior to the replacement of the prosthesis $(8,9)$. Besides the duplication of colour, contour and vitality of natural teeth, an optimal gingival veneering to replace the osseous defects is often necessary (10). The bone augmentation was done but still there was a requirement of veneering to get the natural contour with the adjacent gingival architecture. It was thought that if veneering is not 
done the tooth will appear longer therefore its cervical third was veneered with gingival porcelin. An implant retained prosthesis greatly reduces the necessity for conventional fixed prosthesis supported by natural teeth $(11,12)$. This patient with extensive soft and hard tissue loss required implant supported prosthesis to maintain adequate lip support and oral function. The four osseous integrated dental implants profoundly altered the prosthodontic treatment. Ridge augmentation with endosseous implant placement after reconstruction is an ideal option to treat patients with acquired mandibular defects (13, 14). However an assessment of osseointegration site of these implants requires periodic post insertion evaluation, both clinically and radio graphically (fig-5). The patient should also be made aware of the importance of the oral hygiene protocol to prevent periimplantitis for the long term functioning of the implants.

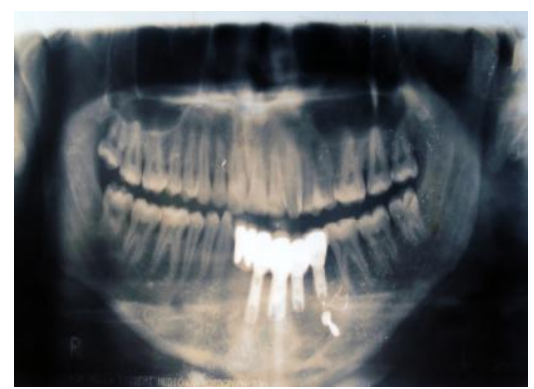

Fig-5: Ortho Phantamo Gram after final cementation of the prosthesis

\section{Conclusion}

This case report presents a patient with significant mandibular bone loss resulting from trauma, rehabilitated using autogenous bone grafts and four implant supported fixed partial denture with gingival tissue veneering. It had psychologically and functionally enabled the patient expectations to cope with comfort, phonetics and esthetics.

\section{References}

1. Maria B. Papageorge, MS Lonnie H. Norris, Rehabilitation of Patients with Reconstructed Mandibles Using Osseointegrated Implants: Clinical Report Int J Oral Maxillofac Implants 1999; 14:118-26.

2. Umut Cakan, Nesrin Anil, Prosthetic rehabilitation of a mandibular gunshot defect with an implant-supported fixed partial denture: A clinical report; J Prosthet Dent 2006; 95:274-9

3. Kung-Rock Kwon, Amit Sachdeo, Achieving immediate function with provisional prostheses after implant placement: A clinical report J Prosthet Dent 2005;93:514-7.

4. Belser UC, Mericske-Stern R, Bernard JP, Taylor TD. Prosthetic management of the partially dentate patient with fixed implant restorations Clin Oral Impl Res 2000: 11 (Suppl.) 126-45.

5. Giinter Hotz, Reconstruction of mandibular delayed nonvascularized free iliac endosseous implants: A clinical report; J Prosthet Dent 1996;76:350-5

6. Robert Cantor and Thomas A Curtis, Prosthetic management of edentulous Mandibulectomy patients. Part 1. Anatomic, Physiologic and psychologic Considerations. J. Prosth Dent. 1971; 25: 446-7.

7. Rosensteel Contemporary fixed prosthodontics, $4^{\text {th }}$ edition, chapter- implant supported fixed prosthesis, page, 420.

8. Richard P. Kinsel,/Robert E. Lamb, Development of Gingival Esthetics in the Edentulous Patient with Immediately Loaded, Single-Stage, Implant-Supported Fixed Prostheses: A Clinical Report Int J Oral Maxillofac Implants 2000; 15:711-21

9. Hidetaka Nakai, Atsushi Niimi, Prosthetic Treatment Using an Osseointegrated Implant After Secondary Bone Grafting of a Residual Alveolar Cleft: A Case Report INT J ORAL Maxillofac Implants 1998; 13:412-5

10. Albert C. F. Leung, Lim K. Cheung, Dental Implants in Reconstructed Jaws: Patients' Evaluation of Functional and Quality-of-Life Outcomes Int $\mathbf{J}$ Oral Maxillofac Implants 2003;18:127-34

11. Behnoush Rashedi, Prosthodontic Treatment with Implant Fixed Prosthesis for a Patient with Ectodermal Dysplasia: A Clinical Report J Prosthodont 2003; 12:198-201

12. Andres Eder, and George Watzek, Treatment of a Patient with Severe Osteoporosis and Chronic Polyarthritis with Fixed ImplantSupported Prosthesis: A Case Report Int J Oral Maxillofac Implants 1999; 14:587-90

13. Zitcssman Clinical and technical aspects of implant-supported restorations in the edentulous maxilla: The fixed partial dentures design Int J_Prosthodont. 1999 Jul-Aug; 12(4):307-12.

14. Ganz The replacement of a unilateral partial denture with an implant-supported fixed prosthesis: a clinical report Implant Dent. 1998; 7(3):159-65 